\title{
Project-based learning: A practical approach to implementing Memsource in the classroom
}

\section{Katrin Herget}

Department of Languages and Cultures / Centre for Languages, Literatures and Cultures, University of Aveiro, Portugal.

\begin{abstract}
Information technology has long become an integral part of today's professional reality and given rise to new job profiles, in response to the changing requirements in many industries. Hence, the knowledge of languages for specific purposes as well as the acquisition of practical competences through project-based learning (PBL) have gained growing significance. Specialized communication skills, coupled with a multilingual professional competence, are a means to address the demands of our today's complex reality. Institutions of higher education more and more feel the urge to prepare their students to new professional challenges and a wide range of employment opportunities. This paper presents a PBL approach by implementing the Computer Aided Translation Tool Memsource in foreign language classes of the Master's course "Languages and Business Relations" at the University of Aveiro. This innovative approach seeks to provide students with a multidisciplinary competence, increase their linguistic proficiency and actively involve them in the decision-making and problem-solving process.
\end{abstract}

Keywords: higher education, Project-based learning (PBL), Computer Aided Translation Tool, Language teaching for specific purposes. 


\section{Introduction}

Information technology has long become an integral part of today's professional reality and given rise to new job profiles, in response to the changing requirements in many industries. Hence, many Institutes of Higher Education have long felt the urge to react to these new dynamic work environments by implementing project-based learning (PBL) into the standard curriculum of their courses. The idea of PBL is to offer students a real-life work environment, providing them with a more dynamic and motivating learning setting. This paper proposes a PBL approach by using the Translation Management System Memsource in the first year Master's course "Languages and Business Relations" at the University of Aveiro. PBL is implemented in the discipline "Applied Project German" that allows the adoption of innovative learning methodologies. We propose to explore how PBL can enhance students' professional skills and in which way the work with Memsource can add value to language learning.

\section{Project-based learning: theoretical framework}

There has been extensive study on the implementation of PBL in a higher education setting. The term centers on student-driven project work, which helps students gain methodological competences in different areas, such as project management, teamwork and problem solving (Dahms, 2014). PBL came up in a response to an imbalance between challenges of today's work environment and students' lack in dealing with such challenges. Higher education institutions have to meet these changing needs, as stated by Uden \& Beaumont (2006): "University education should, ideally, provide students with the necessary skills, values, and attitudes that are essential to cope with the dynamic complexities of the modern world. [...] there is a lack of deep learning about the complex issues and problems that graduates have to face in the real world" (p. 26). Due to a lack of terminological consensus, PBL is herein used in a broad sense, functioning as an umbrella term for a set of innovative teaching activities that focus on the implementation of project work in the classroom.

\section{Memsource and language learning}

Due to the importance of specialized communication skills in our today's information society, in a previous classroom experience students were challenged with small projects on web site localization, which aimed at enabling them to combine linguistic as well as cultural competences with technical skills (Herget, 2018). As shown in this first approach to PBL in the context of localization, Master's students were given the task to localize a company's website from English into their mother tongue Portuguese. However, the approach proposed for this paper goes beyond the localization practice described at an 
earlier stage. The idea behind the implementation of Memsource into language learning was to actively involve students into project work and aimed at preparing them for new professional requirements and changing job profiles within the language industry, such as project managers, localizers, technical writers, etc. The implementation of the CAT tool Memsource into the language learning classroom allows to confront students with a different area of study other than the one they are specializing in. The discovery of such a new area gives them the chance to acquire transversal skills, which are crucial for employability. "Despite their usefulness for translation, CAT tools are seldom used in the context of learning a language, since a good command of a language is usually needed before starting to translate" (Fernández-Parra, 2016, p. 386). The author proposes to expand the usage focus of CAT tools and explore its application in a wider context, i.e. in foreign language classes. From our point of view, the implementation of Memsource through PBL for non-translators represents an interesting methodology, challenging students with a set of hands-on language learning activities.

\section{Memsource - a brief insight into basic functionalities}

Memsource is a cloud-based translation management system, which was developed in the Czech Republic in 2010. It integrates translation memory (TM) technology, machine translation as well as terminology management tools. Memsource, hence, combines all the features of a computer-aided translation tool (so-called CAT tools) that renders translation more efficient. In the specialized translation context, CAT tools are widely used, since the TM feature allows to recycle repetitive text patterns that are typical of specialized texts with domain-specific terminologies. Such systems divide the source text into smaller segments, which are individually displayed and provided with a previous translation during the translation process. TM systems are, thus, databases that store source segments with its translation equivalents for reuse. 


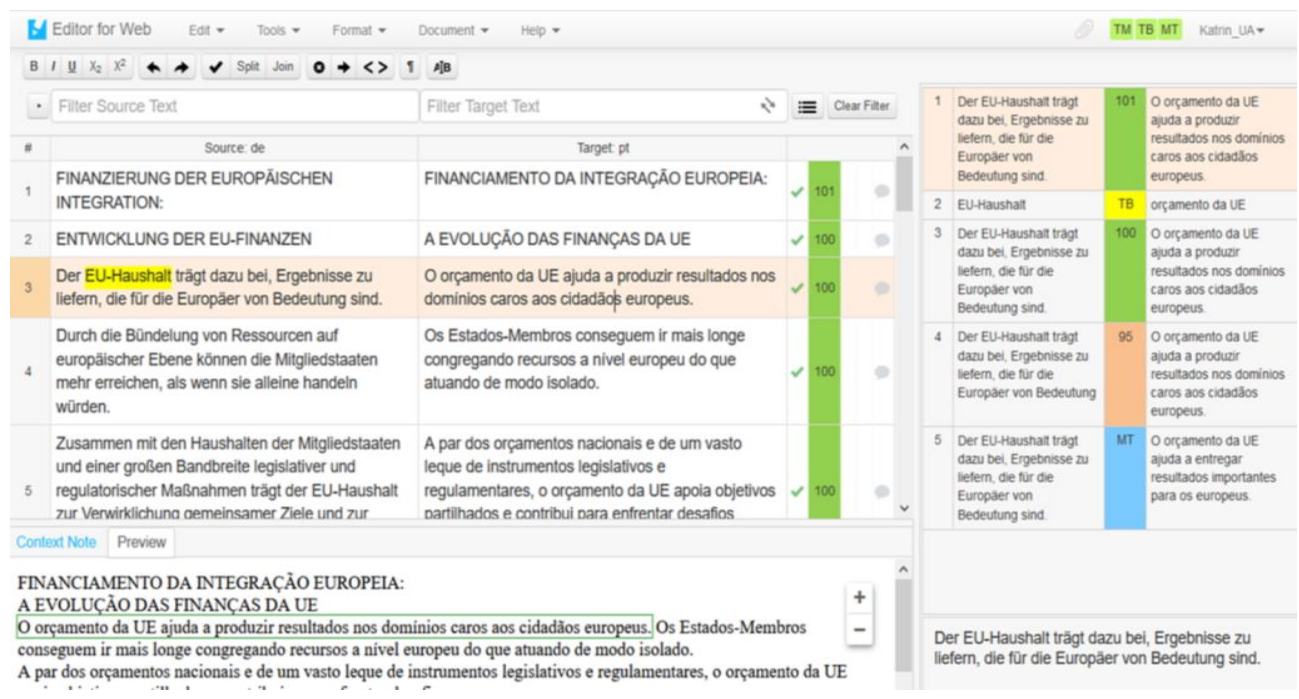

Figure 1. Editor Panel in Memsource

In combination with term recognition tools, alignment of corpora, autosuggest features, integrated term bases, project management, quality assurance, etc., CAT tools are efficient, speed up the translation process and save the translator a lot of time. Particularly important is the fact that Memsource has implemented the latest machine translation advances in its Translate feature, supporting more than 30 machine translation engines and guaranteeing a high quality translation output. These latest technological advances offer new challenges and methodologies for language learning through PBL that have yet to be explored.

\section{The case study}

Due to Memsource's combination of different functionalities and its intuitive interface, it is a very interesting tool to be used in the language classroom, offering a series of practical activities for project learning. In the following, we give a brief description of the PBL experience gained with first year Master's students.

\subsection{Project Management}

In a first approach, students assume the role of project managers without having prior experience in project management. Since project management is considered an emerging profession, having a notion of creating a methodology or a project workflow is crucial for today's work environment. Students can design their own hierarchical workflow structure in Memsource, such as translation, editing, proofreading, and assign a specific person (linguist) for each step. This means that they learn to work in teams and assume responsibility when defining project resources and setting due dates for project activities. 
They also have to dwell on the number of resources assigned to each step, since this may have consequences on the project's success. Memsource allows to create 15 different workflow steps, which is very useful for a precise definition of a project. In a second approach it is possible to enhance group work, where only one student assumes the role of a project manager, whereas the other group members work as linguists or take on other roles. As soon as a task is assigned, the student is notified by e-mail. The project manager can also decide if the same TM is used for all workflow steps or if it is necessary to edit the attributes of a TM. Once the linguist has access to the job, Memsource - as all commercially available CAT tools - provides a statistical analysis of segments, words or characters that are to be translated. Such analysis is fundamental for project planning, since it gives all stakeholders a notion of the amount of work. It lists all information concerning repetitions in the source text, translatable elements as well as fuzzy matches from the TM and machine translation (see Fig. 2).

\begin{tabular}{|c|c|c|c|c|c|c|}
\hline \multirow[t]{2}{*}{ File: $f$} & \multicolumn{6}{|c|}{ Finanzen_DE.doc } \\
\hline & & Segments & Pages & Words & Characters & $\%$ \\
\hline & All & 27 & 1.58 & 377 & 2488 & 100 \\
\hline & Repetitions & 0 & 0 & 0 & 0 & 0 \\
\hline & $101 \%$ & 7 & 0.53 & 121 & 833 & 32.1 \\
\hline+ & $100 \%$ & 11 & 0.38 & 100 & 596 & 26.5 \\
\hline+ & $95 \%-99 \%$ & 0 & 0 & 0 & 0 & 0 \\
\hline+ & $85 \%-94 \%$ & 0 & 0 & 0 & 0 & 0 \\
\hline \multirow[t]{3}{*}{+} & $75 \%-84 \%$ & 0 & 0 & 0 & 0 & 0 \\
\hline & $50 \%-74 \%$ & 1 & 0.13 & 31 & 208 & 8.2 \\
\hline & $0 \%-49 \%$ & 8 & 0.54 & 125 & 851 & 33.2 \\
\hline
\end{tabular}

Figure 2. Project analysis in Memsource

According to the project volume, students can then set a quote, indicating all the costs involved in the project. This part is particularly interesting, since it means that they get a notion on how to calculate the price of a specific workflow step. The calculated cost can then be mailed to the client and only after its final approval, the linguistic work starts. By writing formal emails to potential German clients, students learn to enhance their written communication skills and also acquire an intercultural competence in the field of business communication. The students responsible for the linguistic part then translate the document and send it to the reviewer in charge, who makes the final changes. In accordance with students' foreign language competences, the teacher may introduce a number of different work flow steps, which aim at combining the application of linguistic as well as project management skills. Memsource provides an ideal work environment for practical project management activities, since all project's stakeholders have the possibility to interact 
during a project life cycle. The carrying out of project management activities gives students the opportunity to gain work experience by carrying out a set of hands-on exercises.

\subsection{Datafication and information recycling}

The alignment feature is of particular interest for language learning, since it allows the creation of bilingual (or multilingual) text corpora that are stored in a TM. In times of datafication, in which all kind of data is computerized, the web turns out to be a primary and important source for terminology extraction and corpus building. There is a huge amount of bilingual and multilingual text corpora freely accessible on the web that can be very useful for language learning. Specialized text corpora play an important role in the teaching of languages for specific purposes, since they provide terminological knowledge in a specific domain and a better conceptual understanding of a given area of study. At the beginning of the alignment task, students were provided with a bilingual text in German and Portuguese from the area of Social Policy. The students then were introduced into the work with Memsource's alignment function, which automatically aligns corresponding text segments. Whereas the original text (Portuguese) was presented without any alterations, the translation was modified beforehand in such a sense as that some parts of it where left out. With the creation of such cloze passages, the teacher can test students' linguistic skills, such as lexical and grammatical structures. In the context of TM implementation for language learning, Fernández-Parra (2016, p. 389) suggests "a variety of exercises, ranging from substitution and gap-filling exercises to all kinds of text manipulation exercises, such as partial or complete text reconstruction, reordering words in a sentence, unscrambling, etc.".

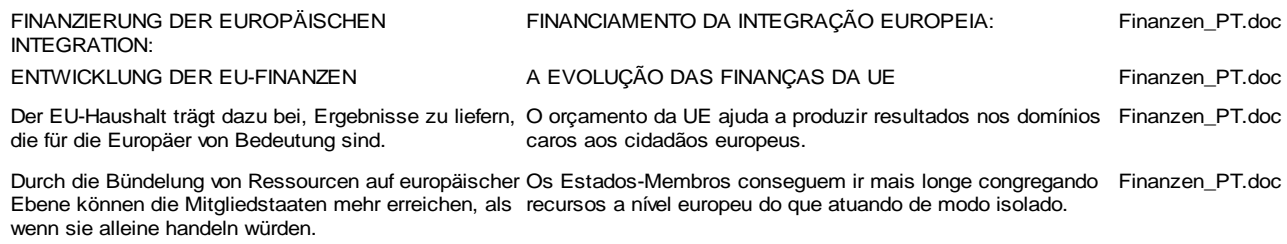

Durch die Bündelung von Ressourcen auf europäischer Os Estados-Membros conseguem ir mais longe congregando Finanzen_PT.doc Ebene können die Mitgliedstaaten mehr erreichen, als recursos a nível europeu do que atuando de modo isolado. wenn sie alleine handeln würden.

Zusammen mit den Haushalten der Mitgliedstaaten und einer großen Bandbreite legislativer und

A par dos orçamentos nacionais e de um vasto leque de instrumentos legislativos e regulamentares, o orçamento da

Finanzen_PT.doc regulatorischer Maßnahmen trägt der EU-Haushalt zur UE apoia objetivos partilhados e contribui para enfrentar Verwirklichung gemeinsamer Ziele und zur Bewältigung gemeinsamer Herausforderungen bei.

Von den Sechzigerjahren, in denen erstmals eine Desde a primeira grande política comum - a política agrícola - Finanzen PT.doc gemeinsame Politik in einem wichtigen Bereich - der na década de 1960 até aos dias de hoje, o orçamento da UE Landwirtschaft - eingeführt wurde, bis zum heutigen evoluiu progressivamente e em paralelo com a construção da Tag hat sich der EU-Haushalt parallel zum Aufbau der União Europeia.

Europäischen Union sukzessive weiterentwickelt. 


\subsection{Quality Assurance - improving linguistic skills}

Given the already mentioned advances in machine translation technology, activities related to machine output evaluation constitute another component that helps to increase students' language proficiency. What is more, in the era of neural machine translation and Deep Learning methods that imitate neural network architectures, post-editing has become a mainstream concern in the professional environment with companies striving to optimize their documentation quality. With that in mind, students were introduced to the Quality Assurance (QA) process carried out in Memsource. The QA feature detects translation errors and terminological inconsistencies in source and target segments by comparing these segments with term base entries, carries out spell checks and identifies wrong formatting and missing tags, etc. Thus, it provides learners of a foreign language with a whole set of attributes that contribute to the improving of text production quality and also increases students' awareness towards the importance of post-editing in today's professional environment.

\section{Conclusions}

This paper explored the implementation of Memsource in the language classroom and aimed at identifying project activities that can be carried out in the foreign language learning when working with a CAT tool. We also wanted to show to what extent the suggested PBL methodology can add value to language learning and prepare students for professional practice. The implementation of Memsource in the Master's course "Languages and Business Relations" offered problem-solving as well as collaborative strategies in real-world scenarios, providing students with new knowledge in a different area of study and promoting the creation of transversal competences. The classroom experience revealed that students with no previous knowledge of CAT tools showed no difficulty in understanding Memsource's basic features and applying them in the professional context. Given the importance of adopting PBL methodologies in higher education settings, the exploration on how Translation Management Systems, such as Memsource, can be used in the language classroom to raise linguistic proficiency of students, constitutes an interesting research question.

\section{References}

Bell, S. (2010). Project-based learning for the 21st century: Skills for the future. Clearing House, 83(2), 39-43. doi:10.1080/00098650903505415

Dahms, M-L. (2014). Problem Based Learning in Engineering Education. In V. Villas- Boas, \& O. Giovannini (Eds.), Attracting Young People to Engineering: ALE 2014 (pp. 10-21). 
Herget, K. (2018). Lokalisierung von Firmen-Websites im Fach 'Angewandtes ProjektDeutsch'. In M. Ellison, M. Pazos Anido, P. Nicólas Martínez \& S. Valente Rodrigues (Eds), As línguas estrangeiras no ensino superior: Propostas didácticas e casos em estudo (pp. 111-124). Porto: APROLÍNGUAS, FLUP e-DITA.

Fernández-Parra, M. (2016). Integrating computer-assisted translation tools into language learning. In A. Pareja-Lora, C. Calle-Martínez, \& P. Rodríguez-Arancón (Eds), New perspectives on teaching and working with languages in the digital era (pp. 385-396). Dublin: Research-publishing.net. doi.org/10.14705/rpnet.2016.tislid2014.450

Uden, L. \& Beaumont, C. (2006). Technology and problem-based learning. Hershey, PA, USA: Information Science Publishing. 